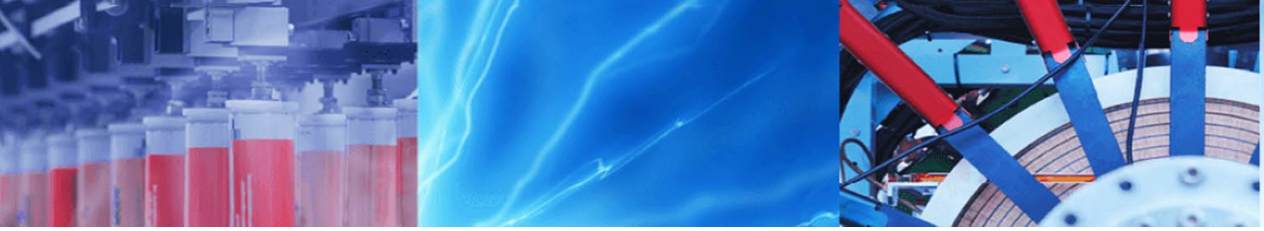

Research Article

\title{
Effect of process conditions on generation of hydrochloric acid and lithium hydroxide from simulated lithium chloride solution using bipolar membrane electrodialysis
}

\author{
Huan Tian ${ }^{1} \cdot$ Xinxing Yan ${ }^{1} \cdot$ Fu Zhou ${ }^{1,2,3,4} \cdot$ Chuan Xu$^{1} \cdot \mathrm{Chao} \mathrm{Li}^{2} \cdot \mathrm{Xin} \mathrm{Chen}^{1} \cdot \mathrm{Xia} \mathrm{He}^{1}$ \\ Received: 16 September 2021 / Accepted: 22 November 2021 \\ Published online: 04 January 2022 \\ (c) The Author(s) $2021 \quad$ OPEN
}

\begin{abstract}
A feasibility study was carried out on generation of hydrochloric acid and lithium hydroxide from the simulated lithium chloride solution using EX3B model bipolar membrane electrodialysis (BMED). The influence of a series of process parameters, such as feed concentration, initial acid and base concentration in device component, feed solution volume, and current density were investigated. In addition, the maximum achievable concentrations of $\mathrm{HCl}$ and $\mathrm{LiOH}$, the average current efficiency, and specific energy consumption were also studied and compared in this paper to the existing literature. Higher $\mathrm{LiCl}$ concentrations in the feed solution were found to be beneficial in increasing the final concentrations of $\mathrm{HCl}$ and $\mathrm{LiOH}$, as well as improving current efficiency while decreasing specific energy consumption. However, when its concentration was less than $4 \mathrm{~g} / \mathrm{L}$, the membrane stack voltage curve of BMED increased rapidly, attributed to the higher solution resistance. Also low initial concentration of acid and base employed in device component can improve the current efficiency. Increasing of the initial concentration of acid and base solution lowered energy consumption. Moreover, a high current density could rapidly increase $\mathrm{HCl}$ and $\mathrm{LiOH}$ concentration and enhance water movements of BMED process, but reduced the current efficiency. The maximum achievable concentration of $\mathrm{HCl}$ and $\mathrm{LiOH}$ generated from $130 \mathrm{~g} / \mathrm{L} \mathrm{LiCl}$ solution were close to $3.24 \mathrm{~mol} / \mathrm{L}$ and $3.57 \mathrm{~mol} / \mathrm{L}$, respectively. In summary, the present study confirmed the feasible application for the generation of $\mathrm{HCl}$ and $\mathrm{LiOH}$ from simulated lithium chloride solution with BMED.
\end{abstract}

Keywords Lithium chloride, Bipolar membrane electrodialysis · Lithium hydroxide · Water movement · Average current efficiency. Specific energy consumption

\section{Introduction}

Lithium is the lightest metal and the least dense solid element in nature. In recently years, lithium and its compounds have a much-diversified industrial applications owe to their special physical and chemical properties. Lithium hydroxide, in particular, is one of the most important lithium feeds, which constitutes a raw material in many commercial applications, including well-known lithium-ion batteries [3, 17], lubricating greases [2], chemical reagents, ceramics and glasses [4]. Owing to the rapid development of the economy and industrialization, it is estimated that the global demand for lithium hydroxide will be 546,400 tons in 2025, and the CAGR will be about $55.28 \%$. Lithium hydroxide is mostly produced from brines or lithium-containing ores. It is difficult to produce battery

$\triangle$ Fu Zhou, zhoufu@tianqilithium.com; $\triangle$ Chuan Xu, xuchuan@tianqilithium.com; $\bowtie$ Chao Li, lichao@tianqilithium.com| ${ }^{1}$ Tianqi Lithium (Shehong) Co., Ltd, Shehong 629200, Sichuan, China. ${ }^{2}$ Tianqi Lithium (Jiangsu) Co., Ltd, Zhangjiagang 215000, Jiangsu, China. ${ }^{3}$ Lithium Resources and Lithium Materials Key Laboratory of Sichuan Province, Tianqi Lithium (Sichuan) Co., Ltd, Shehong 629200, China. ${ }^{4}$ Tianqi Lithium Genesis Technology (shenzhen) Co., Ltd, Shenzhen 518066, Guangdong, China.

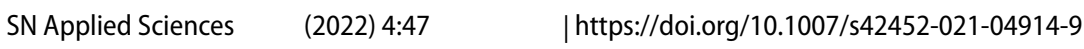


grade lithium hydroxide via brine resources straightaway. It often requires to convert lithium carbonate to lithium hydroxide using a causticization method [24]. Unfortunately, the cost of causticization method is greatly influenced by the price of lithium carbonate and the upfront capital cost of the required is relatively high. The limestone roasting method, as a traditional preparation process, also has some disadvantages of high energy consumption and heavy environmental pollution. On other side, the roasting method $[1,12]$ employs a large number of chemicals, which potentially can introduce other impurities into final products. More recently, battery manufacturers such as Tesla, BYD, BAIC and Daimler have put forward higher requirements on the quality of battery grade lithium hydroxide [33].

Driven by the market demanding, many researchers have made continuous efforts toward improving the quality of lithium hydroxide and reducing energy consumption. Electrodialysis (ED) is emerging as one of the most promising technologies has been investigated as an alternative since 2003s [10,24]. However, no industrial application has been found so far due to its high capital costs and technical obstacles. In the last a few years, bipolar membrane electrodialysis technique was developed and has attracted intensive research attention due to its environmental benignity and energy efficiency [32].

BMED is an electrodialysis method in combination with a bipolar membrane, which can enhance ionic mobilities under the direct current and limit the transmembrane migration of ions by ion selective exchange membrane. It is widely applied in the food, chemical industry and effluent treatment. Fruitful research has been performed using BMED to separate ions from neutral solution and convert them into acid and base [8, 25]. Moreover, the production of sodium hydroxide through BMED from reverse osmosis concentrate $[9,35]$, glyphosate neutralization liquor [27, 34], brominated butyl rubber wastewater [32] and other industrial wastewater [14, 31] have been reported, the results showed that it could be used as a promising and environmentally friendly technique to regeneration sodium hydroxide. The desalination rate of BMED for industrial $\mathrm{NH}_{4} \mathrm{Cl}$ wastewater was $92 \%$, and $\mathrm{HCl}$ and $\mathrm{NH}_{3} \cdot \mathrm{H}_{2} \mathrm{O}$ concentrations obtained from the simulated $\mathrm{NH}_{4} \mathrm{Cl}$ solution was up to $1.58 \mathrm{M}$ and $1.3 \mathrm{M}$, respectively[16]. These reports presented that BMED technique played an extremely important role in generation of inorganic acids and bases and the treatment of industrial high-salinity brine. However, reports about the production of $\mathrm{HCl}$ and $\mathrm{LiOH}$ from Lithium ore leaching solution such as lithium chloride solutions have not been found so far. Therefore, the focus of the research work in this paper was to explore whether BMED technology could be applied in industry as an alternative to traditional technique for the production of lithium hydroxide from lithium ore leaching solution, and to observe the energy consumption and the factors affecting it.

In the present work, simulated $\mathrm{LiCl}$ solution was treated by a EX3B model BMED device for the generation of hydrochloric acid and lithium hydroxide. The effects of process conditions were investigated. Moreover, the water movement in each compartment and the mechanism of affecting the maximum concentration of $\mathrm{HCl}$ and $\mathrm{LiOH}$ were discussed. The present study focused on analyzing the process phenomena and differences of $\mathrm{HCl}$ and $\mathrm{LiOH}$ generated from simulated $\mathrm{LiCl}$ solution, aiming for verifying the potential application of BMED for the regeneration of $\mathrm{LiOH}$ for the production lithium ion battery.

\section{Experimental methods}

\subsection{Reagents and membranes}

Hydrochloric acid (Greagent, 36\%-38\%), Lithium hydroxide monohydrate ( $\mathrm{LiOH}$, solid, $\geq 99.5 \%$ ), lithium chloride (solid, $\geq 99.5 \%$ ), sodium sulfate (Adamas-beta ${ }^{\oplus}, \geq 99.5 \%$ ). Sodium hydroxide (Adamas-beta ${ }^{\oplus}, \geq 98 \%$ ), silver nitrate (Adamas-beta ${ }^{\oplus}, \geq 99 \%$ ), phenolphthalein (IND, Greagent) and potassium chromate (Sigma-Aldrich, $\geq 99.5 \%$ ) were used in the experiment. the reagents of Lithium hydroxide monohydrate and lithium chloride were produced by Tianqi lithium Co., Ltd, Other reagents were purchased from Shanghai Titan Scientific Co., Ltd.

The ions membranes used in the present experiments were BPM-1 (bipolar membranes, ASTOM Co. Ltd, Japan), CM-4 (cation membranes, ASTOM Co. Ltd, Japan) and AM-4 (anion membranes, ASTOM Co. Ltd, Japan). All of the membranes were purchased from Hangzhou Lanran Environmental Technology Co., Ltd (Hangzhou, China). The properties of three kinds of membranes were presented in Tables 1 and 2.

A lab-scale bipolar membrane electrodialysis apparatus (EX3B) was provided by Hangzhou Lanran Environmental Technology Co., Ltd, China. And it was installed according to the BPM-AM-CM-BPM configuration (including acid, base and feed compartments) in the experiment shown in Fig. 1. The membrane stack is comprised of (a) electrodes,

Table 1 The properties of three kinds of membranes

\begin{tabular}{llllll}
\hline $\begin{array}{l}\text { Mem- } \\
\text { brane }\end{array}$ & $\begin{array}{l}\text { Area } \\
\text { resist- } \\
\text { ance }(\Omega \\
\left.\mathrm{cm}^{2}\right)\end{array}$ & $\begin{array}{l}\text { Thickness } \\
(\mathrm{mm})\end{array}$ & $\begin{array}{l}\text { lon } \\
\text { capacity } \\
(\mathrm{meq} / \mathrm{g})\end{array}$ & $\begin{array}{l}\text { Water } \\
\text { content } \\
(\%)\end{array}$ & $\begin{array}{l}\text { Transport } \\
\text { number } \\
(\%)\end{array}$ \\
\hline $\mathrm{AM}-4$ & 1.9 & 0.15 & $1.9-2.5$ & $26-35$ & $\geq 95 \%$ \\
$\mathrm{CM}-4$ & 2.3 & 0.18 & $1.2-1.7$ & $18-29$ & $\geq 90 \%$ \\
\hline
\end{tabular}


Table 2 The properties of bipolar membrane

\begin{tabular}{lllll}
\hline Membrane & $\begin{array}{l}\text { Water split- } \\
\text { ting voltage } \\
(\mathrm{V})\end{array}$ & $\begin{array}{l}\text { Thickness } \\
(\mathrm{mm})\end{array}$ & $\begin{array}{l}\text { Burst } \\
\text { strength } \\
\left(\times 10^{5} \mathrm{pa}\right)\end{array}$ & $\begin{array}{l}\text { Efficiency } \\
(\%)\end{array}$ \\
\hline $\begin{array}{l}\text { Bipolar } \\
\text { membrane } \\
\text { (BP-1) }\end{array}$ & $1-1.2$ & $0.28-0.34$ & $8-10$ & $99 \%$ \\
\hline
\end{tabular}

which are made of titanium electrode coated with ruthenium and iridium, (b) membranes, each membrane had an effective area of $55 \mathrm{~cm}^{2}$ and there are 10 membrane triples in a membrane stack. The spacer channel width was $0.75 \mathrm{~mm}$. The BMED system was connected to an DC power. Driven by three peristaltic pumps, the acid solution $(0.05 \mathrm{~mol} / \mathrm{L} \mathrm{HCl}, 700 \mathrm{~mL})$, base solution $(0.05 \mathrm{~mol} / \mathrm{L} \mathrm{LiOH}$, $700 \mathrm{~mL}$ ) and feed solution $(70-130 \mathrm{~g} \mathrm{LiCl} / \mathrm{L}, 700 \mathrm{~mL})$ and electrode rinse solution $\left(0.5 \mathrm{~mol} / \mathrm{L} \mathrm{Na}_{2} \mathrm{SO}_{4}, 700 \mathrm{~mL}\right.$ ) were circulated in three-compartments system, respectively. Unless otherwise noted, the initial volume of each compartment was $700 \mathrm{~mL}$ and the current density was $60 \mathrm{~mA} /$ $\mathrm{cm}^{2}$.

In this experiment, lithium chloride solution was pumped to a membrane stack as the feed, $\mathrm{Li}^{+}$and $\mathrm{Cl}^{-}$ions in feed compartment migrated through cation membrane into base compartment and anion membranes into acid compartment under a DC voltage, respectively, and then lithium ion and chloride ions combined with hydroxide ions and hydrogen ions generated from water splitting to produce $\mathrm{LiOH}$ and $\mathrm{HCl}$, respectively.

\subsection{Chemical analysis and calculations}

\subsubsection{Chemical analysis}

The $\mathrm{Li}^{+}$ions concentration was analyzed by Atomic Absorption Spectrometry (AA-7050, Shanghai Yoke
Instrument Co., Ltd, China). The $\mathrm{Cl}^{-}$ions concentration was determined by using standard silver nitrate solution as titrant and potassium chromate as indicator. The $\mathrm{HCl}$ concentration was determined by titration with standard sodium hydroxide solution using phenolphthalein as indicator.

\subsubsection{Data processing}

The average current efficiency $(\eta)$ and unit energy consumption (EC) are important standards for evaluation of the electrodialysis performance [36]. The $(\eta)$ is the ratio of practically obtained molar amount of acid/base to that which should theoretically be obtained. The calculation equation is as follows (1) [29]:

$\eta=\frac{z F\left|C_{0} V_{0}-C_{t} V_{t}\right|}{60 N I \Delta t}$

where $z$ is the ion valence. $F$ is Faraday constant $(96,485$ $\mathrm{C} / \mathrm{mol}$ ). $C_{0}$ and $C_{t}$ are the concentration ( $\mathrm{mol} / \mathrm{L}$ ) of $\mathrm{HCl}$ or $\mathrm{LiOH}$ at time 0 and $t(\mathrm{~min})$, respectively. $V_{0}$ and $V_{t}$ are the volume (L) at time 0 and time $\mathrm{t}(\mathrm{min}) . N, \Delta t$ and $\mathrm{I}$ are the number of cell triplets $(N=10)$, time period $(\mathrm{min})$ and current $(A)$, respectively.

The calculation equation of unit energy consumption ( $\mathrm{kWh} / \mathrm{kg}$ ) as follows (2) [29]:

$E C=\frac{\int_{0}^{t} U l d t}{60 M\left(C_{t} V_{t}-C_{0} V_{0}\right)}$

where $t$ is the time (min). $U$ is the stack voltage $(\mathrm{V})$ at time $t$ (min). M stands for the molar mass $(\mathrm{g} / \mathrm{mol})$ of $\mathrm{HCl}$ or $\mathrm{LiOH}$, pumping energy consumption has not been considered.

The liner velocities of acid, base, and feed solution in the compartments are $3.3 \mathrm{~cm} / \mathrm{s}$ and its calculation equation as follows (3)[16]:

Fig. 1 Schematic of BMED for acid-base preparation

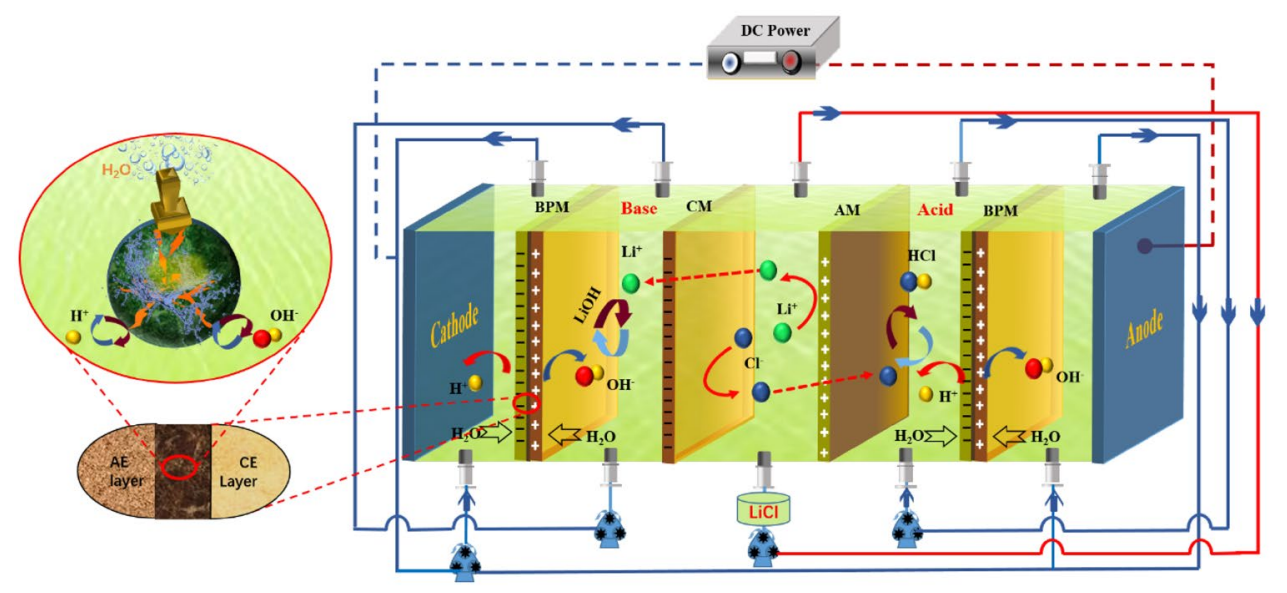


$V=\frac{10^{3} \times Q}{3600 \times N \times W \times d}$

where $V(\mathrm{~cm} / \mathrm{s})$ is the liner velocities, $W(\mathrm{~cm})$ and $d(\mathrm{~cm})$ stand for width of flow section area $(5 \mathrm{~cm})$ and spacer channel width $(0.75 \mathrm{~mm})$, respectively. $\mathrm{Q}(\mathrm{L} / \mathrm{h})$ is the flow rate of acid, base or feed solution ( $45 \mathrm{~L} / \mathrm{h})$.

\section{Results and discussion}

\subsection{Effect of initial LiCl concentration in feed compartment}

In order to examine the influence of the feed concentration, three different concentrations including $70 \mathrm{~g} / \mathrm{L}$, $100 \mathrm{~g} / \mathrm{L}$ and $130 \mathrm{~g} / \mathrm{L}$ were employed.

Figure 2 presents the variation of stack voltage and $\mathrm{Cl}^{-}$concentration at the constant-current density of $60 \mathrm{~mA} / \mathrm{cm}^{2}$. It can be observed clearly that the voltage curve of the membrane stack presented three trends as time goes on: falling stage, steady stage, and rising stage. This phenomenon was considered to be closely related to the total resistance of membrane stack at a constant current in BMED system (including the resistance of membranes and solution). At the beginning stage, the voltage curve dropped gradually indicated that the solution resistance decreased in compartment due to the $\mathrm{H}_{2} \mathrm{O}$ molecules at the interphase layer of the BPM were split into $\mathrm{H}^{+}$and $\mathrm{OH}^{-}$ions, and ions migration from feed solution into acid and base compartments through the anion membrane and cation membrane, respectively. As the experiment progresses, the membrane stack voltage roughly constant for a period of time because the total stack resistance remained unchanged. However, the membrane stack voltage curve increased sharply at the later stage of the

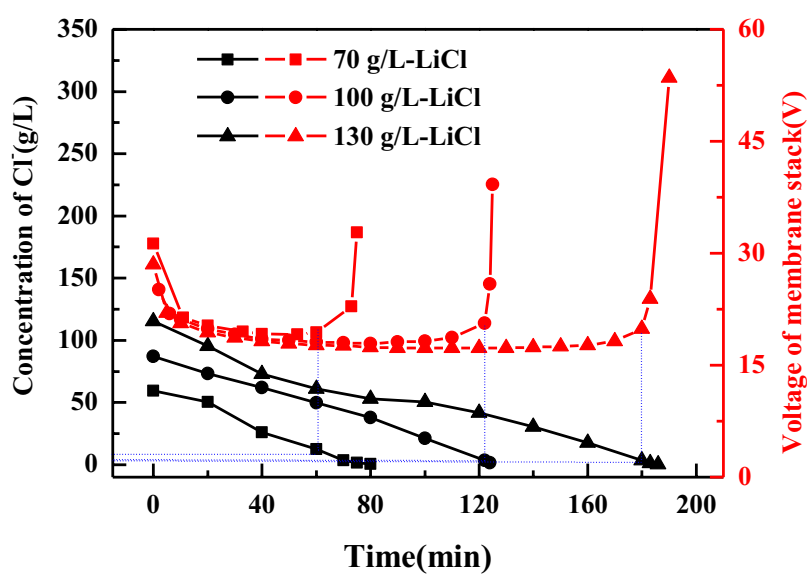

Fig. 2 Variation of stack voltage and $\mathrm{Cl}$ - concentration experiments, this phenomenon can be explained by the depletion of $\mathrm{LiCl}$ in feed compartment (the content of ions dropped to an extremely low level), which lead to the high resistance of the membrane stack. So the changes of membrane stack voltage were closely associated with the increases of acid and base concentration in the beginning of the experiment and the ions depletion in feed solution at the later stage of experiments.

When the membrane voltage of the BMED system rises rapidly, the samples of feed solution in feed compartment were taken out and the $\mathrm{Cl}^{-}$ions concentration was analyzed. It can be observed from Fig. 2 that the $\mathrm{LiCl}$ concentration contained in feed compartment dropped to less than $4 \mathrm{~g} / \mathrm{L}$, which was consistent with the "inflection point" of membrane stack voltage. That indicated that when the $\mathrm{LiCl}$ concentration contained in feed compartment was less than $4 \mathrm{~g} / \mathrm{L}$, the BMED system is no longer suitable for treatment because the lower ionic content could lead to the higher solution resistance, which resulted in the higher energy consumption of BMED system. The low-concentration $\mathrm{LiCl}$ solution can be further concentrated by other membrane equipment to achieve reuse purposes. while the concentrated solution obtained could also be used to produce $\mathrm{HCl}$ and $\mathrm{LiOH}$ with BMED.

The concentration of $\mathrm{HCl}$ and $\mathrm{LiOH}$ solution with different feed concentrations were compared, and the results were shown in Fig. 3. It was found that the $\mathrm{HCl}$ and $\mathrm{LiOH}$ concentration increased generally as time elapsed. As it can be seen, when the feed solution containing $\mathrm{LiCl}$ of $70 \mathrm{~g} / \mathrm{L}, 100 \mathrm{~g} / \mathrm{L}$, and $130 \mathrm{~g} / \mathrm{L}$ after continuously running for 80,120 and, $180 \mathrm{~min}$, the $\mathrm{HCl}$ and $\mathrm{LiOH}$ concentration were $1.41 \mathrm{~mol} / \mathrm{L}, 1.83 \mathrm{~mol} / \mathrm{L}, 2.24 \mathrm{~mol} / \mathrm{L}$ and $1.26 \mathrm{~mol} / \mathrm{L}$, $1.71 \mathrm{~mol} / \mathrm{L}, 2.06 \mathrm{~mol} / \mathrm{L}$, respectively. The $\mathrm{HCl}$ solution obtained in acid compartment could meet the requirements of the ion exchange resin regeneration $[38,39]$ and the cleaning of reverse osmosis membrane $[18,20$,

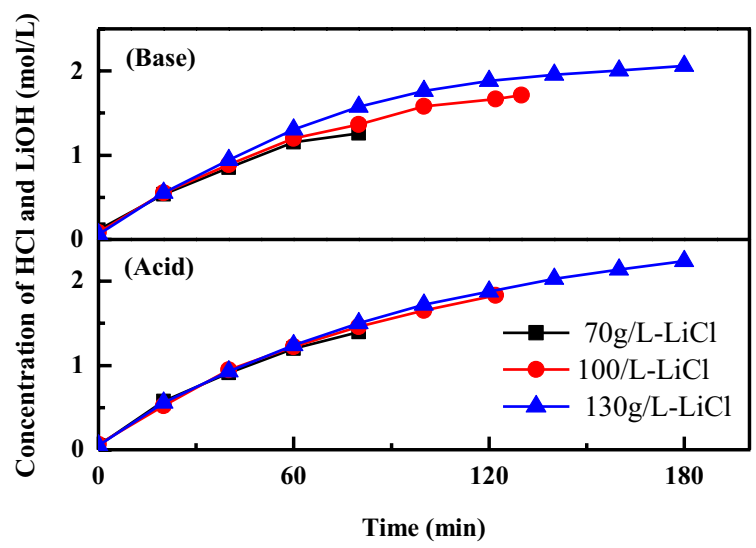

Fig. 3 Acid and base concentration curves at different initial feed concentrations 


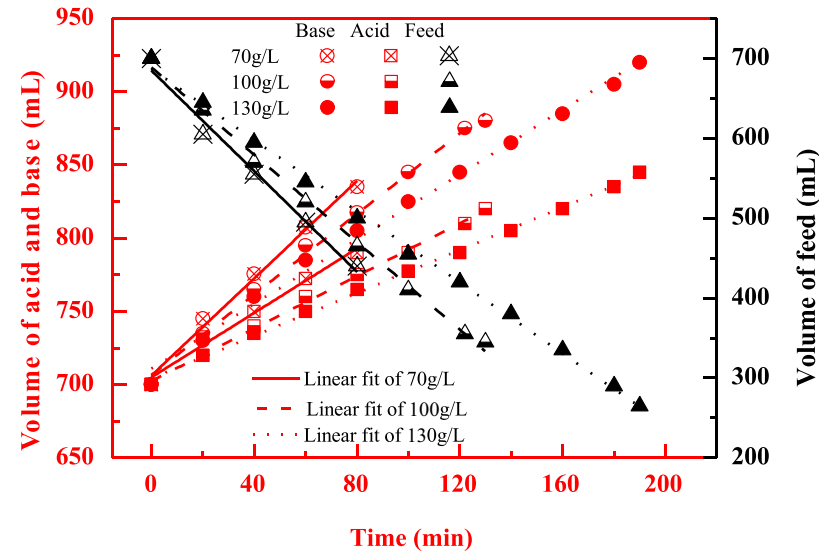

Fig. 4 Variation of solution volume in feed, acid and base compartments

21]. Moreover, the $\mathrm{HCl}$ solution can also be used for more applications by evaporation or other methods, and the $\mathrm{LiOH}$ solution obtained can be used to produce batterygrade lithium hydroxide monohydrate $\left(\mathrm{LiOH} \cdot \mathrm{H}_{2} \mathrm{O}\right)$ products by evaporation and recrystallization. Figure 3 shows that the concentration of $\mathrm{HCl}$ and $\mathrm{LiOH}$ at the initial stage increased faster than that at the later stage, which was caused by the decrease of ionic content and water electricity penetration [28]. The decrease of ionic content in feed compartment would inevitably result in less $\mathrm{Li}^{+}$and $\mathrm{Cl}^{-}$ions migrating from feed compartment to the adjacent compartments. Furthermore, $\mathrm{Cl}^{-}$and $\mathrm{Li}^{+}$ions in the form of hydration ions migrated from feed compartment into the adjacent compartment through the anion membrane and cation membrane, respectively, which resulted in the increase of acid and base solution volume (the volume variation was shown in Fig. 4). Therefore, the growth rate of $\mathrm{HCl}$ and $\mathrm{LiOH}$ concentration were delayed. These results meant that increasing the concentration of $\mathrm{LiCl}$ in feed compartment was helpful to obtain higher acid and base concentrations.

Figure 4 shows the variation of solution volume in feed, acid, and base compartments with different feed concentrations. The solution volume in the feed compartment decreased linearly while the acid and base volume increased linearly as time elapsed. The reduced volume of solution in feed compartment was roughly equal to the sum of the volumetric increment of solution in acid and base compartment, which was consistent with the research results of Lizuka [7]. It can be observed from Fig. 4 that there was a significant difference in the slope of linearized curves, indicating that the change rate of solution volume in feed, acid and base compartments decreased with the increase of the initial feed concentration. The volume variation of solution in acid, base and feed compartments was mainly due to water movements driven by the concentration diffusion and electro-osmosis (counter-ions migration) $[11,19]$. The electro-osmosis influence on water migration was dominant, which could drive the counterions in the form of hydrated ions to migrate into the acid and base compartments. Therefore, the volume of feed compartment displayed a decreasing trend while that of acid and base compartments increasing. Furthermore, it was also observed that the volume of base compartment increased faster than the volume of the acid compartment. This phenomenon was closely related to the number of ions transferred across the membranes, which is higher in the cation membrane.

Figure 5 shows that the variation of $\mathrm{pH}$ and conductivity of feed solution with different initial $\mathrm{LiCl}$ concentration. It can be observed that the conductivity of feed solution decreased gradually to 0 at the end of the experiments, which indicated that the ions in the feed solution were almost depleted as time elapsed. However, lower concentration of $\mathrm{LiCl}$ solution was not conducive to the concentration increase of $\mathrm{HCl}$ and $\mathrm{LiOH}$. It was also proved that the simulated $\mathrm{LiCl}$ solution can realize the goal of the generation of hydrochloric acid and lithium hydroxide monohydrate and desalination simultaneously by BMED. Figure $5 \mathrm{a}$ indicated that the initial $\mathrm{LiCl}$ solution was always weakly alkaline. While the $\mathrm{pH}$ dropped sharply in feed solution might be due to the higher $\mathrm{H}^{+}$ions leakage though the anion membrane at the beginning of the experiment, According to the literature $[5,23,37]$ protons can be easily transported across anion membrane from acid compartment into adjacent feed compartment by the so-called tunnel mechanism. When the process ended, the increase in the $\mathrm{pH}$ value of feed solution might be ascribed to the concentration polarization phenomenon, because the $\mathrm{LiCl}$ concentration contained in the feed compartment was too low at that period [13].

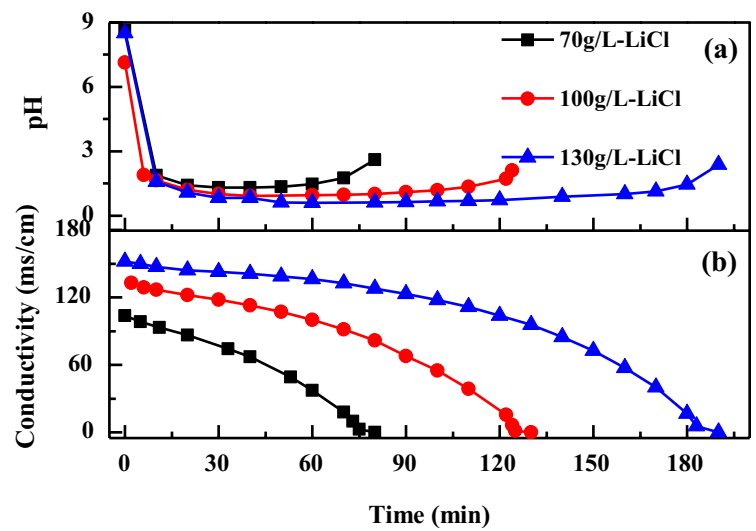

Fig. 5 Variation of the conductivity (b) and $\mathrm{pH}$ (a) with feed concentration 


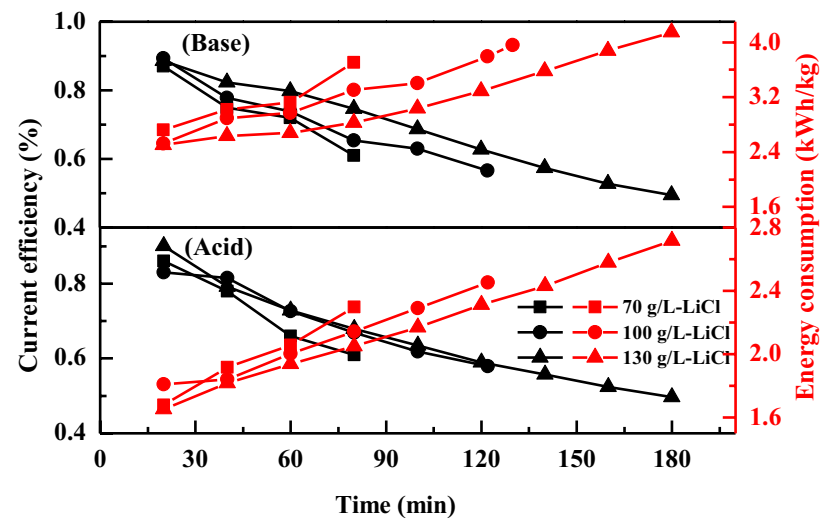

Fig. 6 Efficiency and energy consumption curves of $\mathrm{HCl}$ and $\mathrm{LiOH}$

Figure 6 demonstrated the influence of the feed concentration on the current efficiency $(\eta)$ and unit energy consumption (EC) when the current density was $60 \mathrm{~mA} /$ $\mathrm{cm}^{2}$. It was found that the higher initial concentration of $\mathrm{LiCl}$ was beneficial to increase $\eta$ and reduce EC. According to the literature, the $\mathrm{EC}$ was $5.5 \mathrm{kWh} / \mathrm{kg}$ for the acid $\left(\mathrm{H}_{2} \mathrm{SO}_{4}\right)$ and $4.8 \mathrm{kWh} / \mathrm{kg}$ for the base $(\mathrm{NaOH})$ with the initial concentration of $75 \mathrm{~g} \mathrm{Na}_{2} \mathrm{SO}_{4} / \mathrm{L}$ at the constant current density of $60 \mathrm{~mA} / \mathrm{cm}^{2}$ [29], and the EC of $60 \mathrm{~g} / \mathrm{L}$ $\mathrm{NH}_{4} \mathrm{Cl}$ was treated by BMED was $9.1 \mathrm{kWh} / \mathrm{kg}$ for $\mathrm{NH}_{3} \cdot \mathrm{H}_{2} \mathrm{O}$ and $8.5 \mathrm{kWh} / \mathrm{kg}$ for $\mathrm{HCl}$ when current density was $48 \mathrm{~mA} /$ $\mathrm{cm}^{2}$ [16], while EC of the acid $(\mathrm{HCl})$ and base $(\mathrm{LiOH})$ with the initial concentration of $70 \mathrm{~g} \mathrm{LiCl} / \mathrm{L}$ demonstrated in Fig. 6 were 2.2 and $3.7 \mathrm{kWh} / \mathrm{kg}$, respectively, which are much lower than those reported in the literature [16, 29]. At a current density of $30 \mathrm{~mA} / \mathrm{cm}^{2}$, the $\eta$ of $100 \mathrm{~g} / \mathrm{L}$ $\mathrm{NaCl}$ was about $65 \%$ for the base $(\mathrm{NaOH})$ and $84 \%$ for the acid $(\mathrm{HCl})$ with initial acid and base concentration of $0.05 \mathrm{M}$ [22], which were lower than the $\eta$ values in Fig. 6. One possible explanation for these results stems from the fact that the dissolution of lithium chloride in water was an exothermic reaction and the present room temperatures are above $28{ }^{\circ} \mathrm{C}$ during the summer season. The higher temperature of the initial $\mathrm{LiCl}$ solution in salt compartment led to the lower EC and higher $\eta$ in the BMED process. Although the influence of temperature on electrodialysis performance is complex because the mass transfer process involved, these phenomena indicated that the mobility of ions in adjacent compartment increases with the increase of temperature probably, which had a significant impact on the decrease in the resistance of the membrane stack. Additionally, the $\mathrm{EC}$ and $\eta$ were also associated with other factors, such as operating conditions and characteristics of membranes (BM, AEM, and CEM) $[25,30]$.

\subsection{Influences of initial concentration of $\mathrm{HCl}$ and LiOH}

In order to have a lower resistance in membrane stack, $\mathrm{HCl}$ and $\mathrm{LiOH}$ were added to the acid and base compartments to investigate the effect of initial concentration on generation of $\mathrm{HCl}$ and $\mathrm{LiOH}$ when the current density was $60 \mathrm{~mA} / \mathrm{cm}^{2}$, and results are shown in Fig. 7. The $\mathrm{HCl}$ and $\mathrm{LiOH}$ concentration increased slightly with the increase of initial concentration of acid and base, while the growth of $\mathrm{HCl}$ and $\mathrm{LiOH}$ concentration was inhibited by the higher initial concentration of acid and base compartments. Which might be resulted from the leakage of $\mathrm{H}^{+}$and $\mathrm{OH}^{-}$ions through the ions membrane. At the beginning of the experiment, more $\mathrm{H}^{+}$and $\mathrm{OH}^{-}$ions in the initial acid and base compartments resulted in more ions leakage. After that, the concentration gradient of feed and acid/base compartments increased gradually as the feed concentration decreased and the acid/base concentration increased, which resulted in the high driving force for the ion's reverse diffusion according to Fick's first law. Furthermore, this can also be explained that the higher initial concentration of $\mathrm{HCl}$ and $\mathrm{LiOH}$ could lead to the increase of transfer resistance from feed compartment into acid or base compartment, which could inhibit the increase of $\mathrm{HCl}$ and $\mathrm{LiOH}$. Therefore, increasing initial concentration of acid and base maybe not a good way to improve the yield of $\mathrm{HCl}$ and $\mathrm{LiOH}$ generated from $\mathrm{LiCl}$ solution by BMED.

Figure 8 illustrates the current efficiency $(\eta)$ and energy consumption (EC) curves of BMED at different initial concentrations. It was found that the $\mathrm{EC}$ of $\mathrm{HCl}$ and $\mathrm{LiOH}$ has no significant increase as the increase of initial acid and base concentration, but a slight decrease. The reason for this was that a higher initial concentration of acid and base will inevitably lead to

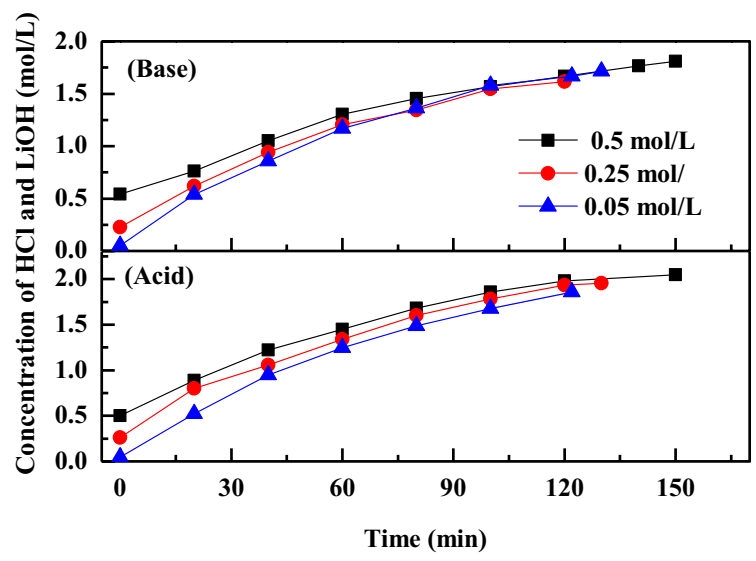

Fig. 7 Effect of initial acid and base concentration on generation of $\mathrm{HCl}$ and $\mathrm{LiOH}$ 


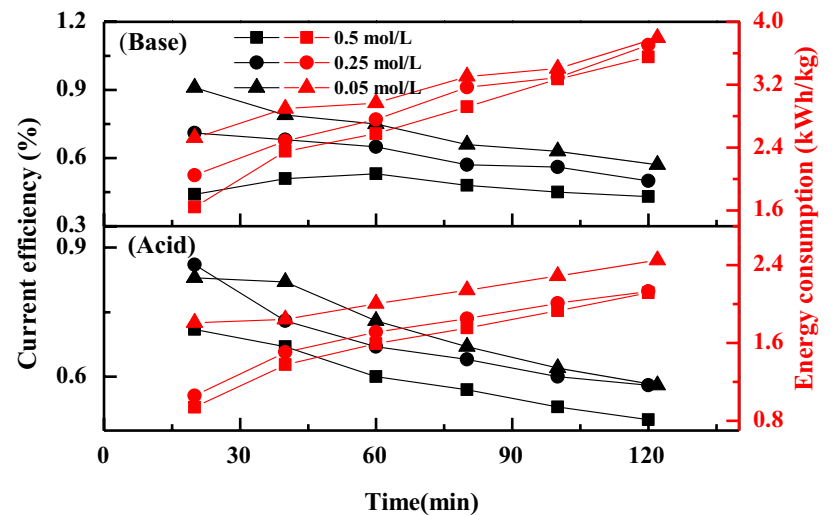

Fig. 8 The efficiency $(\eta)$ and energy consumption (EC) of $\mathrm{HCl}$ and $\mathrm{LiOH}$ at different initial concentration

a decrease in the membrane stack resistance since the increase of initial conductivity in acid and base solution. However, with the initial concentration of acid and base compartment increasing further, the ratio of membrane stack resistance to the total resistance decreased greatly. Therefore, the EC of acid and base decreased in a much smaller magnitude in BMED system. In terms of the $\eta$ curve, which had been reduced from 70 to $60 \%$ for the acid $(\mathrm{HCl})$ and $61 \%$ to $47 \%$ for the base $(\mathrm{LiOH})$ by increasing the initial concentration of acid and base solution from $0.05 \mathrm{~mol} / \mathrm{L}$ to $0.5 \mathrm{~mol} / \mathrm{L}$ after running $120 \mathrm{~min}$. This was caused by the fact that the growth rate of $\mathrm{HCl}$ and $\mathrm{LiOH}$ concentration was inhibited by the higher initial concentration of acid and base in device component.
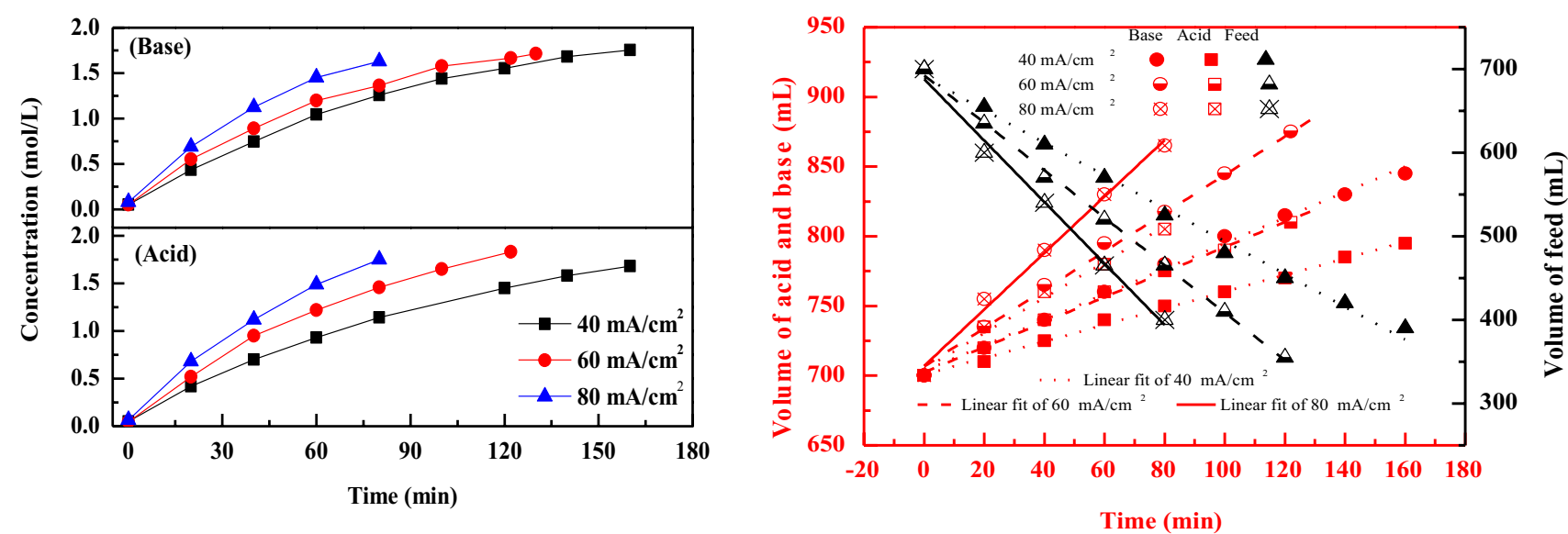

Fig. 9 Variation of $\mathrm{HCl}$ and $\mathrm{LiOH}$ concentration (left) and solution volume in feed, acid and base compartments under different current densities (right) 


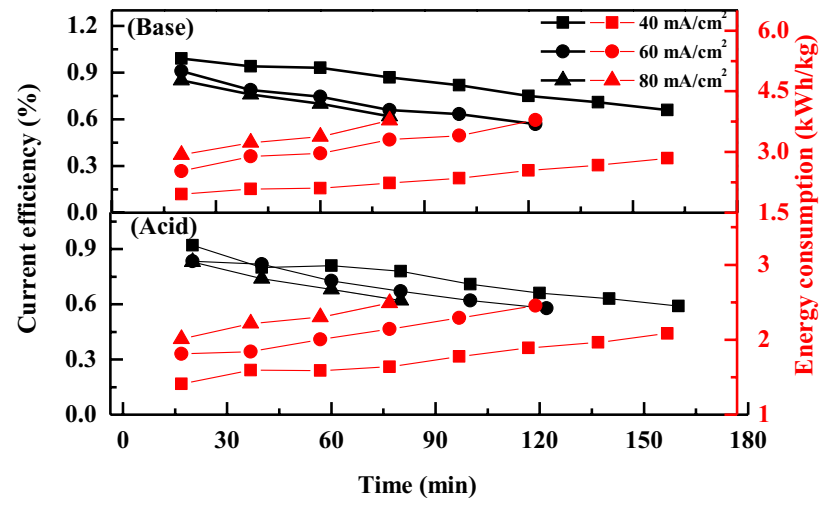

Fig. 10 The efficiency and energy consumption of $\mathrm{HCl}$ and $\mathrm{LiOH}$ at different current density

to the fact that $\mathrm{H}^{+}$has greater inherent mobility than $\mathrm{OH}^{-}$, which resulted in more $\mathrm{H}^{+}$with a smaller radius of hydrated ions, leaking from the acid compartment to the feed compartment $[15,26]$. In addition, current density had a greater impact on water migration. As shown in Fig. 9 (right), the degree of water migration increased as the current density increased. Therefore, when a larger current density was applied, desalinated solution of a smaller volume and a larger volume of acid and base solution can be obtained within the same experimental time.

Figure 10 demonstrates the influence of current density on the $\eta$ and EC of BMED process. It can be observed that the lower current density was helpful to increase the $\eta$ and reduce $\mathrm{EC}$ of $\mathrm{HCl}$ and $\mathrm{LiOH}$ generated from $\mathrm{LiCl}$, which was completely opposite to the trend of different feed concentrations shown in Fig. 6 . Furthermore, there was a tiny difference between the $\eta$ curves of $60 \mathrm{~mA} / \mathrm{cm}^{2}$ and $80 \mathrm{~mA} /$ $\mathrm{cm}^{2}$. However, the gap increased significantly when the current density dropped to $40 \mathrm{~mA} / \mathrm{m}^{2}$. For example, when the operating time was $80 \mathrm{~min}$ and current density were 40,60 and $80 \mathrm{~mA} / \mathrm{cm}^{2}, \eta$, and $\mathrm{EC}$ for $\mathrm{LiOH}$ were 0.8 and $2.38 \mathrm{kWh} / \mathrm{kg}, 0.65$ and $3.31 \mathrm{kWh} / \mathrm{kg}$, and 0.62 and 3.78 $\mathrm{kWh} / \mathrm{kg}$, respectively. To sum up, this phenomenon was mainly related to the transmembrane migration of ions in adjacent compartments and the dissociation of $\mathrm{H}_{2} \mathrm{O}$ molecules at the interphase layer of the BPM. The higher the current density was, the faster the velocity of ions flux was. When the ions adsorbed on the membrane were depleted, it would directly cause the increase of stack resistance and even $\mathrm{H}_{2} \mathrm{O}$ molecules splitting. Moreover, the higher current density was also helpful to inhibit ions unexpected transfer, especially at the later stage of the experiments. The energy consumption curve of $\mathrm{HCl}$ and $\mathrm{LiOH}$ increased gradually with the increase of current density during BMED process, which resulted from that a large part of the electricity was consumed to overcome the membrane stack resistance. Therefore, the appropriate high current density should be selected for the BMED system when considering daily acid and base output and the process cost.

\subsection{Effects of feed volume and the maximum achievable concentration of $\mathrm{HCl}$ and $\mathrm{LiOH}$}

The lower concentration of $\mathrm{LiCl}$ in feed compartment would greatly affect the final concentration of $\mathrm{HCl}$ and $\mathrm{LiOH}$, especially at the end of the experiments when $\mathrm{LiCl}$ concentration dropped to a much lower level. Therefore, in order to further investigate the effect of initial feed solution volume on a generation of $\mathrm{HCl}$ and $\mathrm{LiOH}$, the experiments of $70 \mathrm{~g} / \mathrm{L} \mathrm{LiCl}$ were performed with the different initial feed solution volumes of $700 \mathrm{~mL}$ and $2100 \mathrm{~mL}$ in BMED system.

Figure 11 illustrates that the influence of different initial volumes of $\mathrm{LiCl}$ solution on concentration of $\mathrm{HCl}$ and $\mathrm{LiOH}$. It could be seen from Fig. 11 that the concentration of $\mathrm{HCl}$ and $\mathrm{LiOH}$ were $2.52 \mathrm{~mol} / \mathrm{L}$ and $2.5 \mathrm{~mol} / \mathrm{L}$ at the initial feed volume of $2100 \mathrm{~mL}$, which were much higher than that with the initial volume of $\mathrm{LiCl}$ solution was $700 \mathrm{~mL}$. This was caused by the fact that the higher total mole number of $\mathrm{LiCl}$ in feed compartment necessarily led to the increase of $\mathrm{Li}^{+}$and $\mathrm{Cl}^{-}$ions from feed compartment to transmembrane migrate into the adjacent compartment in BMED process. Furthermore, it was found that the concentration curve of $V_{\text {feed }}: V_{\text {acid or base }}=1: 1$ did not completely coincide with the curve of $V_{\text {feed: }}: V_{\text {acid or base }}=3: 1$ in the period range $40 \sim 80 \mathrm{~min}$. Which mainly due to less ion migration and intensification of the concentration difference polarization phenomenon when the initial feed volume was $700 \mathrm{~mL}$ because the $\mathrm{LiCl}$ concentration in feed compartment was too low at that period. Therefore, it may be an effective method to increase the final concentration of $\mathrm{HCl}$ and $\mathrm{LiOH}$ generated from $\mathrm{LiCl}$ solution by increasing the initial

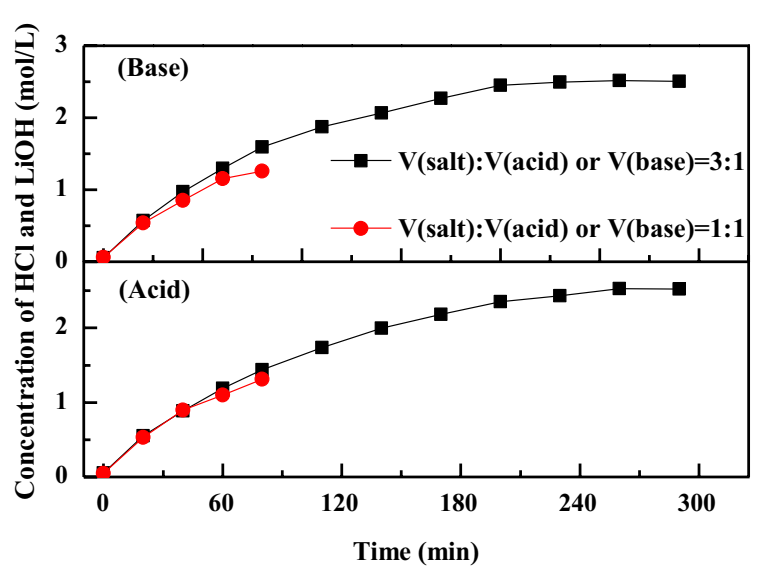

Fig. 11 Variation of $\mathrm{HCl}$ and $\mathrm{LiOH}$ concentration under different feed volumes 


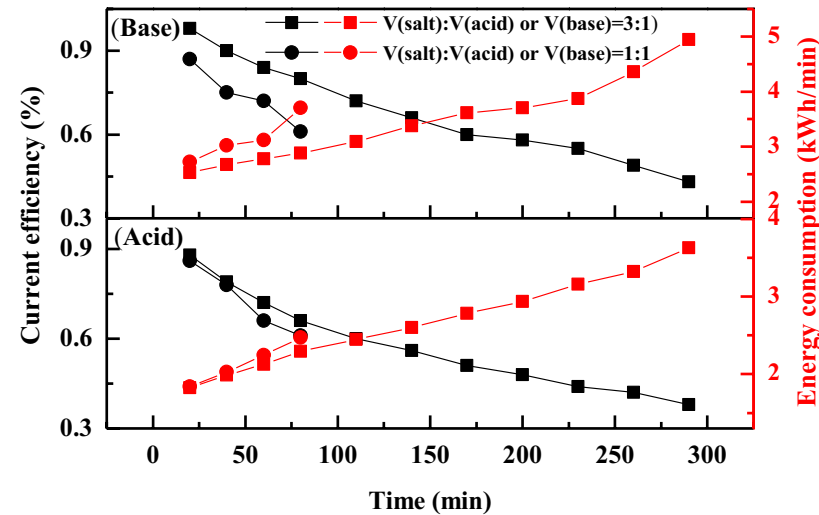

Fig. 12 The influence of different feed volume on efficiency and energy consumption

volume of feed compartment or increasing initial concentration of feed compartment.

Figure 12 demonstrates the influence of initial feed volume on the efficiency and unit energy consumption. Increasing the initial volume of feed solution was helpful to improve the performance of electrodialysis process, because it can increase efficiency and reduce energy consumption of $\mathrm{HCl}$ and $\mathrm{LiOH}$ generated from $\mathrm{LiCl}$ solution. It was found that when the initial feed volume increased from 700 to $2100 \mathrm{~mL}$, the current efficiency of the BMED process had been improved from 61 to $66 \%$ for acid $(\mathrm{HCl})$ and $61 \%$ to $80 \%$ for base $(\mathrm{LiOH})$, respectively, while the unit energy consumption of $\mathrm{LiOH}$ had been reduced from 2.1 to $1.6 \mathrm{kWh} / \mathrm{kg}$ after run $80 \mathrm{~min}$. The main reason should be that the content of ions in feed compartment had no significant change after run $80 \mathrm{~min}$ when the feed solution volume was $2100 \mathrm{~mL}$, in contrast with the feed solution volume of $700 \mathrm{~mL}$, which had a significant decrease in ions content of feed solution when the total mole number of $\mathrm{LiCl}$ in the salt solution dropped to a much lower level. Therefore, an appropriate increase in the solution volume of feed was helpful to generate a higher concentration of $\mathrm{HCl}$ and $\mathrm{LiOH}$ with BMED.

The maximum achievable concentration of $\mathrm{HCl}$ and $\mathrm{LiOH}$ was also considered to be the important parameter to evaluate the performance of membranes in BMED system. In addition to the limitations of the bipolar membrane, for a given application, the selection of anion exchange membranes was also the most important since their inferior permselectivity and chemical stability compared with cation ion exchange membranes.

In order to maintain a constant concentration of $\mathrm{LiCl}$ in feed compartment during the experiment, a higher concentration of lithium chloride solution was added continuously to feed compartment to balance the decrease of concentration and volume in the feed compartment by a peristaltic pump. Figure 13 shows that the maximum achievable concentration of $\mathrm{HCl}$ and $\mathrm{LiOH}$ with the initial concentration of $130 \mathrm{~g} \mathrm{LiCl} / \mathrm{L}$ at the current density of $80 \mathrm{~mA} / \mathrm{cm}^{2}$. It can be observed from Fig. 13 that the growth rate of $\mathrm{HCl}$ and $\mathrm{LiOH}$ concentration at the end of the experiment was significantly lower than that in the initial stage, resulted from the ions reverse diffusion and the increase of ions transfer resistance. The maximum concentration of $\mathrm{LiOH}$ generated from $\mathrm{LiCl}$ was about $3.58 \mathrm{~mol} / \mathrm{L}$ after continuously running for $360 \mathrm{~min}$. However, the maximum concentration of $\mathrm{HCl}$ was slightly lower than the corresponding concentration of $\mathrm{LiOH}$. It was also proved that the maximum concentration of $\mathrm{HCl}$ and $\mathrm{LiOH}$ obtained from $\mathrm{LiCl}$ solution were mainly determined by the properties of the anion ions exchange membrane which has limited retention of protons since the so-called proton-tunneling mechanism. Similarly, a higher concentration of hydroxide ions can permeate from the base compartment through the cation ions membrane, but to a lesser extent. The net result is that the hydrogen ions and hydroxide ions generated from the splitting of water migrating from the acid or base compartment through the ions membrane to neutralize each other in feed compartment. Which resulted in the lower current utilization of BMED process. Therefore, the selection of an appropriate output concentration of $\mathrm{HCl}$ and $\mathrm{LiOH}$ was favor to reduce the leakage and reverse diffusion of ions.

\section{Conclusions}

A lab-scale BMED system for the generation of $\mathrm{HCl}$ and $\mathrm{LiOH}$ from simulated lithium chloride solution was presented in the study. The influence of regents and operating parameters were investigated. The results indicate that the higher initial concentration of $\mathrm{LiCl}$ was beneficial to increase the concentration of $\mathrm{HCl}$ and $\mathrm{LiOH}$ and average current efficiency, while decreasing the specific energy consumption

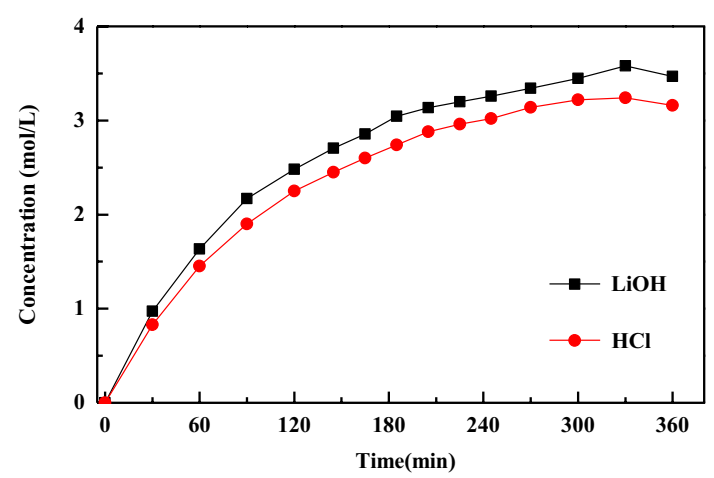

Fig. 13 The maximum achievable concentration of $\mathrm{HCl}$ and $\mathrm{LiOH}$ in BMED system 
of $\mathrm{HCl}$ and $\mathrm{LiOH}$. The stack voltage increased rapidly when the $\mathrm{LiCl}$ concentration within the feed compartment was less than the "inflection point concentration" about $4 \mathrm{~g} / \mathrm{L}$. when changing the initial volume of $70 \mathrm{~g} / \mathrm{L} \mathrm{LiCl} \mathrm{from} 700$ to $2100 \mathrm{~mL}$, the concentration of $\mathrm{HCl}$ and $\mathrm{LiOH}$ increase from $1.31 \mathrm{~mol} / \mathrm{L}$ and $1.26 \mathrm{~mol} / \mathrm{L}$ to $2.53 \mathrm{~mol} / \mathrm{L}$ and $2.52 \mathrm{~mol} / \mathrm{L}$, respectively, while the unit energy consumption had been reduced from $3.68 \mathrm{kWh} / \mathrm{kg}$ to $2.81 \mathrm{kWh} / \mathrm{kg}$ for the base (LiOH) after run $80 \mathrm{~min}$. Moreover, a high current density could rapidly increase $\mathrm{HCl}$ and $\mathrm{LiOH}$ concentration and enhance water movements of BMED process, but reduce the current efficiency.

The higher initial concentration of acid and base was in favored to improve the final concentration of them, but an excessively high initial concentration was adverse to the growth of $\mathrm{HCl}$ and $\mathrm{LiOH}$ concentration. The maximum concentration of $\mathrm{HCl}$ and $\mathrm{LiOH}$ were close to $3.24 \mathrm{~mol} / \mathrm{L}$ and $3.57 \mathrm{~mol} / \mathrm{L}$, respectively, obtained at a constant concentration of $130 \mathrm{~g} \mathrm{LiCl} / \mathrm{L}$ and the current density of $80 \mathrm{~mA} / \mathrm{cm}^{2}$. The produced $\mathrm{HCl}$ can potentially be used for resin regeneration and lithium chloride conversion from lithium sulfate, and $\mathrm{LiOH}$ can be treated for the production of battery-grade $\mathrm{LiOH}$. In summary, the results confirm the feasibility for the generation of $\mathrm{HCl}$ and $\mathrm{LiOH}$ from simulated $\mathrm{LiCl}$ solution by BMED and provide a favorable reference for the optimization of process parameters.

Acknowledgements The authors would like to thank Mr. Chuan Xu, for to provide the necessary support in this work. Also, we thank to PhD Fu Zhou and PhD Chao Li for their help in data analysis and revision of work.

Authors' contributions HT designed the study, undertook most of the experimental work, and drafted the manuscript. $X Y$ and $X C$ undertook part of the experimental work. $\mathrm{HD}$ and $\mathrm{XH}$ provide support for chemical analysis and testing. $\mathrm{CL}$ and $\mathrm{CX}$ contributed substantially to the revising of this work. FZ acquired the funding used to support this work, and provided substantial support of the design, drafting and revision of this work.

Funding This work was supported by the National Key R\&D Program of China (G20200136011) and Sichuan Science and Technology Program (2019YFQ0027, 2020YFS0547 and 2020ZHCG0024).

Availability of data and materials The datasets used or analysed during the current study are available from the corresponding author on reasonable request.

\section{Declarations}

Conflict of interest All authors declare that there are no conflicts of interest.

Open Access This article is licensed under a Creative Commons Attribution 4.0 International License, which permits use, sharing, adaptation, distribution and reproduction in any medium or format, as long as you give appropriate credit to the original author(s) and the source, provide a link to the Creative Commons licence, and indicate if changes were made. The images or other third party material in this article are included in the article's Creative Commons licence, unless indicated otherwise in a credit line to the material. If material is not included in the article's Creative Commons licence and your intended use is not permitted by statutory regulation or exceeds the permitted use, you will need to obtain permission directly from the copyright holder. To view a copy of this licence, visit http://creativecommons. org/licenses/by/4.0/.

\section{References}

1. Barbosa LI, González JA, Ruiz MDC (2015) Extraction of lithium from $\beta$-spodumene using chlorination roasting with calcium chloride. Thermochim Acta 605:63-67. https://doi.org/10.1016/j. tca.2015.02.009

2. Chaduneli ZK, Shibryaev SB, Esitashvili VA, Fuks IG (1987) Influence of alkalinity on effectivness of additives in lithium greases. Chem Tech Fuels Oil 23:28-30. https://doi.org/10.1007/BF007 25642

3. Dong T, Zhang L, Yu X, Zhao Z, Dong Y (2011) Synthesis and characterization of gradient cathode material for lithium-ion batteries. Adv Mater Res 391-392:1435-1439. https://doi.org/ 10.4028/www.scientific.net/AMR.391-392.1435

4. Esaka T, Adachi Y (2014) Electrode property of sintered ceramic based on $\mathrm{CaMnO} 3$ in $\mathrm{LiOH}$ aqueous solution. J Mater Sci Chem Eng 02:15-21. https://doi.org/10.4236/msce.2014.24002

5. Fu L, Gao X, Yang Y, Fan A, Hao H, Gao C (2014) Preparation of succinic acid using bipolar membrane electrodialysis. Sep Purif Technol 127:212-218. https://doi.org/10.1016/j.seppur.2014.02. 028

6. Huang C, Xu T, Feng H, Li Q (2009) Win?Win coupling in electrodialysis with bipolar membranes (EDBM) for cleaner production. Ind Eng Chem Res 48:1699-1705. https://doi.org/10.1021/ie801 $192 \mathrm{k}$

7. lizuka A, Yamashita $Y$, Nagasawa $H$, Yamasaki A, Yanagisawa $Y$ (2013) Separation of lithium and cobalt from waste lithium-ion batteries via bipolar membrane electrodialysis coupled with chelation. Sep Purif Technol 113:33-41. https://doi.org/10. 1016/j.seppur.2013.04.014

8. İpekçi D, Altıok E, Bunani S, Yoshizuka K, Nishihama S, Arda M, Kabay N (2018) Effect of acid-base solutions used in acid-base compartments for simultaneous recovery of lithium and boron from aqueous solution using bipolar membrane electrodialysis (BMED). Desalination 448(2018):69-75. https://doi.org/10. 1016/j.desal.2018.10.001

9. Ibáñez R, Pérez-González A, Gómez P, Urtiaga AM, Ortiz I (2013) Acid and base recovery from softened reverse osmosis (RO) brines. Exp Assess Using Model Concentr Desalinat 309:165170. https://doi.org/10.1016/j.desal.2012.10.006

10. Jiang C, Wang Y, Wang Q, Feng H, Xu T (2014) Production of lithium hydroxide from lake brines through electro-electrodialysis with bipolar membranes (EEDBM). Ind Eng Chem Res 53:61036112. https://doi.org/10.1021/ie404334s

11. Jiang C, Wang Q, Li Y, Wang Y, Xu T (2015) Water electro-transport with hydrated cations in electrodialysis. Desalination 365:204212. https://doi.org/10.1016/j.desal.2015.03.007

12. Kuang G, Li H, Hu S, Jin R, Liu S, Guo H (2015) Recovery of aluminium and lithium from gypsum residue obtained in the process of lithium extraction from lepidolite. Hydrometallurgy 157:214-218. https://doi.org/10.1016/j.hydromet.2015.08.020

13. Krol JJ, Wessling M, Strathmann H (1999) Concentration polarization with monopolar ion exchange membranes: current-voltage 
curves and water dissociation. J Membrane Sci 162:145-154. https://doi.org/10.1016/S0376-7388(99)00133-7

14. Kroupa J, Kincl J, Cakl J (2015) Recovery of $\mathrm{H} 2 \mathrm{SO} 4$ and $\mathrm{NaOH}$ from $\mathrm{Na} 2 \mathrm{SO} 4$ by electrodialysis with heterogeneous bipolar membrane. Desalin Water Treat 56:3238-3246. https://doi.org/ 10.1080/19443994.2014.980972

15. Lv Y, Yan H, Yang B, Wu C (2018) Bipolar membrane electrodialysis for the recycling of ammonium chloride wastewater: Membrane selection and process optimization. Chem Eng Res Des 138:105-115. https://doi.org/10.1016/j.cherd.2018.08.014

16. Li Y, Shi S, Cao H, Wu X, Zhao Z, Wang L (2016) Bipolar membrane electrodialysis for generation of hydrochloric acid and ammonia from simulated ammonium chloride wastewater. Water Res 89:201-209. https://doi.org/10.1016/j.watres.2015.11.038

17. Liu T, Liu Z, Kim G, Frith J, Grey C (2017) Understanding LiOH chemistry in a ruthenium catalyzed Lim2 battery. Angew Chem Int Ed 56(50):16057-16062. https://doi.org/10.1002/anie.20170 9886

18. Madaeni SS, Mohamamdi T, Moghadam MK (2001) Chemical cleaning of reverse osmosis membranes. Desalination 134:7782. https://doi.org/10.1016/S0011-9164(01)00117-5

19. Mier MP, IbanEz R, Ortiz I (2008) Influence of ion concentration on the kinetics of electrodialysis with bipolar membranes. Sep Purif Technol 59: 197-205. https://doi.org/10.1016/j.seppur. 2007.06.015

20. Madaeni SS, Samieirad S (2010) Chemical cleaning of reverse osmosis membrane fouled by wastewater. Desalination 257:8086. https://doi.org/10.1002/apj.387

21. Madaeni SS, Mansourpanah Y (2004) Chemical cleaning of reverse osmosis membranes fouled by whey. Desalination 161:13-24. https://doi.org/10.1016/S0011-9164(04)90036-7

22. Reig M, Casas S, Valderrama C, Gibert O, Cortina JL (2016) Integration of monopolar and bipolar electrodialysis for valorization of seawater reverse osmosis desalination brines: Production of strong acid and base. Desalination 398:87-97. https://doi.org/ 10.1016/j.desal.2016.07.024

23. Rottiers T, Ghyselbrecht K, Meesschaert B, Van DB, Pinoy B (2014) Influence of the type of anion membrane on solvent flux and back diffusion in electrodialysis of concentrated $\mathrm{NaCl}$ solutions. Chem Eng Sci 113:95-100. https://doi.org/10.1016/j.ces.2014.04. 008

24. Ryabtsev AD, Nemkov NM, Kotsupalo NP, Serikova LA (2004) Preparation of high-purity lithium hydroxide monohydrate from technical-grade lithium carbonate by membrane electrolysis. Russ J Appl Chem 77(7):1108-1116. https://doi.org/10.1023/B: RJAC.0000044158.61704.93

25. Bunani S, Arda M, Kabay N, Yoshizuka K, Nishihama S (2017) Effect of process conditions on recovery of lithium and boron from water using bipolar membrane electrodialysis (BMED). Desalination 416:10-15. https://doi.org/10.1016/j.desal.2017. 04.017

26. Shen J, Huang J, Liu J, Ye W, Lin J, Bart VDB (2013) The use of BMED for glyphosate recovery from glyphosate neutralization liquor in view of zero discharge. J Hazard Mater 260(2013):660667. https://doi.org/10.1016/j.jhazmat.2013.06.028

27. Shen J, Huang J, Ruan H, Wang J, Bart VDB (2014) Techno-economic analysis of resource recovery of glyphosate liquor by membrane technology. Desalination 342:118-125. https://doi. org/10.1016/j.desal.2013.11.041

28. Tanaka Y (2004) Overall mass transport and solution leakage in an ion-exchange membrane electrodialyzer. J Membrane Sci 235(1-2):15-24. https://doi.org/10.1016/j.memsci.2004.01.013

29. Tran ATK, Mondal P, Meesschaert LJY, B, Pinoy L, Bart VDB, (2015) Simultaneous regeneration of inorganic acid and base from a metal washing step wastewater by bipolar membrane electrodialysis after pretreatment by crystallization in a fluidized pellet reactor. J Membrane Sci 473:118-127. https://doi.org/10.1016/j. memsci.2014.09.006

30. Wang X, Wang Y, Zhang X, Feng H, Xu T (2013) In-situ combination of fermentation and electrodialysis with bipolar membranes for the production of lactic acid: Continuous operation. Bioresour Technol 147:442-448. https://doi.org/10.1016/j.biort ech.2013.08.045

31. Wei Y, Li C, Wang Y, Xu Z, Li Q, Xu T (2012) Regenerating sodium hydroxide from the spent caustic by bipolar membrane electrodialysis (BMED). Sep Purif Technol 86:49-54. https://doi.org/10. 1016/j.seppur.2011.10.019

32. Wei Y, Wang Y, Zhang X, Xu TW (2013) Comparative study on the treatment of simulated brominated butyl rubber wastewater by using bipolar membrane electrodialysis (BMED) and conventional electrodialysis (ED). Sep Purif Technol 110:164-169. https://doi.org/10.1016/j.seppur.2013.03.028

33. Weimer L, Braun T, Hemdt AV (2019) Design of a systematic value chain for lithium-ion batteries from the raw material perspective. Resour Policy 64:101473-101473. https://doi.org/10.1016/j. resourpol.2019.101473

34. Wang $X$ (2013) The feasible study on thereclamation of the glyphosate neutralization liquor by bipolar membrane electrodialysis. Dissertation, Ocean University of China

35. Yang L, Yao J, Wang J (2017) Desalination of concentrated wastewater from reverse osmosis by bipolar membrane electrodialysis. Water Treat 98:108-114. https://doi.org/10.5004/dwt.2017. 21704

36. Yang Y, Gao X, Fan A, Fu L, Gao C (2014) An innovative beneficial reuse of seawater concentrate using bipolar membrane electrodialysis. J Membr Sci 449:1 19-126. https://doi.org/10.1016/j. memsci.2013.07.066

37. Zhao $Y$, Wang $H$, Li Y, Wang $M$, Xiang $X$, An integrated membrane process for preparation of lithium hydroxide from high $\mathrm{Mg} / \mathrm{Li}$ ratio salt lake brine. Desalination $493: 114620-114633$, https:// doi.org/10.1016/j.desal.2020

38. Zhan Y, Yu J (2010) Cause analysis and solving countermeasure of the acid and alkali consumption in the regeneration of ion exchange resin in the primary defeeding system. Industr Water Treatment 30:81-83. https://doi.org/10.1080/14697688.2012. 738930

39. Zhang W (2013) Influence of regeneration method on regeneration degeree of cation exchange resins. Thermal Power Gener 42(2013):88-89. https://doi.org/10.3969/j.issn.1002-3364.2013. 03.088

Publisher's Note Springer Nature remains neutral with regard to jurisdictional claims in published maps and institutional affiliations. 